JURNAL BASICEDU

Research \& Learning in Elementary Education

https://jbasic.org/index.php/basicedu

\title{
EFEKTIVITAS PROBLEM BASED LEARNING DAN TWOSTAY TWO STRAY DALAM PENCAPAIAN HASIL BELAJAR
}

\author{
Wisnu Darmawan ${ }^{1}$, Nyoto Harjono ${ }^{2}$ \\ Program Studi Pendidikan Guru Sekolah Dasar, Universitas Kristen Satya Wacana, Salatiga, Indonesia \\ e-mail : wisnudarmawan94@gmail.com ${ }^{1}, \underline{\text { har.john59@gmail.com }{ }^{2}}$
}

\begin{abstract}
Abstrak
Penelitian ini bertujuan untuk mengetahui apakah terdapat perbedaan efektivitas penerapan model pembelajaran Two Stay Two Stray dan Problem Based Learning terhadap pencapaian hasil belajar Tema 8 Kelas 4 SD Negeri Blotongan 02 dan SD Negeri Sidorejo Lor 05 Gugus Diponegoro, kecamatan Sidorejo, Kota Salatiga. Penelitian ini termasuk dalam penelitian eksperimental semu yang menggunakan pendekatan non-equivalent control group design. Dalam menganalisis data dilaksanakan uji beda melalui Independent Sampel T-Test. Hasil uji beda menunjukkan nilai signifikansi (2-tailed) post-test hasil belajar peserta didik sebesar 0,000 lebih kecil dari 0,005 $(0,000<0,005)$ sehingga disimpulkan bahwa terdapat perbedaan efektivitas yang signifikan antara model pembelajaran Two Stay Two Stray dan Problem Based Learning terhadap pencapain hasil belajar peserta didik pada Tema 8 Kelas 4 SD. Nilai rata-rata post-test hasil belajar kelas eksperimen lebih besar dibandingkan dengan kelas kontrol sehingga dapat disimpulkan bahwa model pembelajaran Two Stay Two Stray lebih efektif dibandingkan model pembelajaran Problem Based Learning.
\end{abstract}

Kata Kunci: Two Stay Two Stray, Problem Based Learning, Hasil Belajar,Tema 8

\begin{abstract}
This research aims to determine whether there is a difference in the effectiveness of the implementation of Two Stay Two Stray models and Problem Based Learning on the achievement of learning outcomes Theme 8 Grade 4 Elementary School Blotongan 02 and Elementary School Sidorejo Lor 05 Diponegoro cluster, Sidorejo subdistrict, city of Salatiga. This research is included in pseudo-experimental studies using a nonequivalent control group design approach. In analyzing the data are conducted different tests through Independent sample T-Test. Different test results show the significance value (2-tailed) post-Test of students ' learning outcomes amounting to 0.000 smaller than $0.005(0,000<0,005)$ To conclude that there is a significant difference in effectiveness between Two Stay Two Stray and Problem Based Learning models of student learning outcomes in theme 8 of Class 4. The average post-test result of the experiment class learning results is greater Compared to the control class so it can be in.
\end{abstract}

Keywords: Two Stay Two Stray, Problem Based Learning, Learning Outcomes, Theme8

@ Jurnal Basicedu 2020

$\triangle$ Corresponding author :

Address : Kaliceret, Ds.Mrisi RT.01RW.05 KC.Tanggungharjo

Email : wisnudarmawan94@gmail.com

Phone : 085831461855

ISSN 2580-3735 (Media Cetak)

ISSN 2580-1147 (Media Online) 
403 Efektivitas Problem Based Learning dan Two Stay Two Stray dalam pencapaian hasil belajarWisnu Darmawan, Nyoto Harjono

\section{PENDAHULUAN}

Secara bertingkat, pada tingkat satuan pendidikan dasar (SD/MI) diberlakuka Kurikulum SD/MI tahun 2013. Pendekatan yang digunakan dalam Kurikulum SD/MI tahun 2013 tersebut menggunakan pendekatan tematik integratif. Pembelajaran tematik adalah pendekatan pembelajaran yang mengintegrasikan berbagai kompetensi dari berbagai mata pelajaran. Pengintegrasian tersebut dilakukan dalam 3 (tiga) hal, yaitu integrasi sikap, keterampilan dan pengetahuan dalam proses pembelajaran serta pengintegrasian berbagai konsep dasar yang berkaitan (Dokumen kurikulum 2013).

Menurut Peraturan Menteri Pendidikan dan Kebudayaan Nomor 65 Tahun 2013 tentang Standar Proses dinyatakan bahwa standar proses pembelajaran sepenuhnya diarahkan pada pengembangan ketiga ranah (sikap, pengetahuan dan keterampilan) secara utuh/holistik, artinya pengembangan ranah yang satu tidak bisa dipisahkan dengan ranah lainnya sehingga melahirkan kualitas peserta didik yang mencerminkan keutuhan penguasaan sikap, pengetahuan dan keterampilan. Penjelasan tersebut tidak jauh dengan penjelasan yang tertuang dalam lampiran Peraturan Menteri Pendidikan dan Kebudayaan Nomor 81A tahun 2014 tentang Implementasi Kurikulum bahwa kegiatan pembelajaran merupakan proses pendidikan yang memberikan kesempatan pada peserta didik untuk mengembangkan dan meningkatkan potensi, kemampuan baik dalam sikap, pengetahuan dan keterampilan yang diperlukan untuk hidup, bermasyarakat dan bernegara. Kurikulum 2013 mengatur pelaksanaan pembelajaran yang digunakan pada tingkat SD/MI sederajat menggunakan pembelajaran tematik terpadu. Hal ini ditegaskan kembali dalam Permendikbud No. 65 tahun 2013 tentang Standar Proses bahwa pembelajaran tematik terpadu di SD/MI/SDLB/Paket A disesuaikan dengan tingkat perkembangan peserta didik.

Model-model pembelajaran yang sesuai dengan karakteristik Kurikulum 2013 adalah model pembelajaran langsung, model pembelajaran kooperatif, pembelajaran kontekstual, model pembelajaran penemuan terbimbing, problem based learning, dan model sejenis (Depdikbud, 2014: 246). Arends dalam Jamil Suprihatiningrum (2014: mendefinisikan bahwa pembelajaran Problem Based Learning merupakan pembelajaran yang mana peserta pidik mengerjakan permasalahan yang otentik dengan tujian untuk menyusun pengetahuan mereka sendiri, mengembangkan inkuiri dan keterampilan berpikir tingkat lebih tinggi, mengembangkan kemandirian dan percaya diri. Menurut Trianto (2011: 67) Dinyatakan bahwa model pembelajaran PBL adalah model pembelajaran yang didasarkan pada banyaknya permasalahan yang membutuhkan penyelidikan autentik yakni penyelididkan yang memerlukan penyelesaian secara nyata dari permasalahan yang nyata. Menuru Sujana dalam Abdurrozak, dkk (2016) Dinyatakan bahwa Problem Based Learning merupakan model pembelajaran yang menyajikan berbagai permasalahan dikehidupan nyata sehingga dengan berbagai permasalhan tersebut peserta didik dapat menjadikan hal 
404 Efektivitas Problem Based Learning dan Two Stay Two Stray dalam pencapaian hasil belajarWisnu Darmawan, Nyoto Harjono

tersebut sebagai dasar penyelidikan untuk menyelesaikan masalah. Problem Based Learning merupakan model pembelajaran digunakan untuk memfokuskan peserta didik dalam sebuah permasalahan secara menyeluruh yang digunakan dalam melakukan penyelidikan serta dapat memahami pembelajaran melalui kegiatan penyelidikan Mulyasa (2014:145). Menurut Hosnan (2014: 301) dinyatakan bahwa Problem Based Learning memilki lagkah-langkah pembelajaran yaitu: 1. Mengenalkan peserta didik pada permasalahan. 2. Mengkelompokkan peserta didik agar belajar. 3.membimbing peseta didik saat melakukan kegiatan investigasi individu dan kelompok. 4. Menolah dan menyajikan hasil karya kelompok. 5. Karya yang dihasilnkan selanjutya dianalisis dan dievaluasi.

Model pembelajaran lain yang juga memiliki potensi seperti model pembelajaran Problem Based Learning yaitu model pembelajaran Two Stay Two Stray. Menurut Shoimin (2014 : 222) Dinyatakan bahwa Two Stay Two Stray adalah model pembelajaran dua peserta didik tinggal dalam kelompok dua orang peserta didik bertamu ke kelompok lain. Menurut Spencer dalam Huda (2013:207) dinyatakan bahwa Two Stay Two Stray adalah sistem pembelajaran berkelas dengan tujuan agar peserta didik dapat saling bekerja sama, bertanggung jawab, saling membantu memecahkan masalah, dan juga dapat mendorong satu sama lain untuk berpartisipasi. Selain itu Two Stay Two Stray dapat melatih peserta didik untuk dapat beinteraksi secara aktif dengan peserta didik yang lain. Masalah atau kasus disesuaikan dengan materi bidang studi yang menjadi pusat belajar atau kasus tersebut diberikan kepada peserta didik untuk diselesaikan secara individu atau berkelompok. Menurut Sutikno (2014:104) dinyatakan bahwa Two Stay Two Stray memilki lagkah-langkah pembelajaran yaitu: 1. Empat Peserta didik dalam kelompok dapat bekerja sama. 2. Selanjutnya dua peserta didik dalam kelompok segera meninggalkan kelompoknya lalu bertamu ke kelompok yang lain. 3 . Kemudian dua peserta didik yang tinggal di dalam kelompok berfungsi sebagai pemberi informasi kepada peserta didik yang bertamu. 4 . Setalah itu peserta didik yang bertamu kembali lagi ke kelompok awal untuk melaporkan informasi yang didapatkan dari kelmpok lain. 5. Terakhir masing-masing kelompok mendiskusikan dan mencocokan hasil karya mereka

Berdasarkan penjelasan dari beberapa para ahli di atas maka dapat disimpulkan bahwa terdapat persamaan dari model pembelajaran Problem Based Learning dan Two Stay Two Stray adalah pembelajaran yang didasarkan pada suatu permasalahan agar didiskusikan baik secara individu maupun dengan kelas untuk menemukan penyelesaian masalah yang sesuai dengan permasalahan yang telah ditentukan.

Beberapa penelitian terdahulu berhasil membuktikan bahwa model Problem Based Learning efektif diterapkan dalam mempengarui hasil belajar. Hal ini dibuktikan melalui penelitian yang dilakukukan oleh Asrika Maha Dewi, 2012, telah melakukan penelitian tentang Pengaruh Model Pembelajaran Problem Based Learning Berbantuan Media Video Terhadap Hasil Belajar IPA Kelas IV SD Negeri Pergung 
405 Efektivitas Problem Based Learning dan Two Stay Two Stray dalam pencapaian hasil belajarWisnu Darmawan, Nyoto Harjono

hasil belajar IPA peserta didik yang mengikuti model pembelajaran PBL berbantuan media video berada pada tingkat kategori tinggi diatas rata-rata sebesar 30,56, (2) hasil belajar IPA peserta didik yang mengikuti pembelajaran konvensional berada pada tingkat kategori sedang (diatas rata-rata sebesar 21,97), (3) terdapat perbedaan yang signifikan hasil belajar IPA antara kelompok peserta didik yang mengikuti pembelajaran dengan model pembelajaran PBL berbantuan media video dan kelompok peserta didik yang mengikuti pembelajaran dengan pembelajaran konvensional (t-hitung $=8,50>\mathrm{t}$ tabel $=2,00)$.

Sedangkan penelitian yang dilakukan oleh Risnayanti R. Pengaruh Model Pembelajaran Kooperatif Tipe Two Stay Two stray Dan Tipe Giving Question And Getting Answer Terhadap Hasil belajar Dan Hasil Belajar Peserta didik Pada Materi Sistem Ekskresi membuktikan bawa model Two Stay Two Stray memberikan pengaruh Hal ini ditunjukan dengan nilai signifikan sebesar 0,000 di bawah nilai alfa 0,05 .

Berdasarkan hasil penelitian di atas, kedua model efekif atau terdapat efektifitas untuk digunakan dalam mempengaruhi hasil belajar. Menurut Said dalam Dewi (2014) dikatakan bahwa efektivitas artinya berusaha agar mencapai tujuan yang telah ditetapkan supaya sesuai dengan kebutuhan yang diperlukan, serta sesuai dengan rencana, meliputi dalam pengunaan data, sarana, maupun waktunya atau berusaha melalui aktivitas tertentu baik secara fisik maupun non fisik atau memperoleh hasil yang maksimal baik secara kuantitatif maupun kualitatif.
Hasil belajar menurut Purwanto (2014: 48) dinyatakan bahwa hasil belajar adalah kemampuan yang muncul pada pesera didik setelah mengikuti pembelajaran. hasil belajar merupakan potensi yang diperoleh peserta didik melalui proses pembelajaran Susanto (2015: 5). Namun apakah dengan menerapkan Two Stay Two Stray dan Problem Based Learning efektif jika digunakan dalam pembelajaran tematik Kelas 4 Tema 8 Daerah Tempat Tinggalku Subtema 1 Linkungan Tempat Tingalku Pembelajaran 1, apakah juga dapat berpengaruh pada hasil belajar peserta didik. Dimulai dari keragu-raguan tersebut alasan penelitian ini dilakukan. Menarik apabila penelitian ini membandingkan hasil belajar tematik Two Stay Two Stray dan problem based learning. Efektivitas Problem Based Learning dan Two Stay Two Stray Dalam Pencapaian Hasil Belajar Tema 8 Peserta Didik Kelas 4 Semester 2 SD Kota Salatiga Tahun Pelajaran 2019/2020.

\section{METODE}

Penelitian ini mengunakan kuasi eksperimen dengan desain Nonequivalent Control Group Design. Penggunakan desain Nonequivalent Control Group Design ini terdapat kelas eksperimen dan kelas kontrol yang tidak dipilih secara matching only. Populasi dalam penelitian ini terdiri atas seluruh peserta didik kelas 4 SD Negeri Blotongan 02 dan SD Negeri Sidorejo Lor 05 Gugus Dipnegoro pada Tahun ajaran 2019/2020. Kedua sekolah tersebut terletak di kecamatan Sidorejo, Kota Salatiga, Jawa Tengah. Sempel yang digunakan dalam peneitian ini ialah peserta didik kelas 4 SD Negeri Blotongan 02 sebagai kelas Eksperimen 
yang berjumlah 33 peserta didik. Sedangkan kelas kontrol pada penelitian ini mengambil sempel kelas 4 SD Negeri Sidorejo Lor 05 yang berjumlah 31 peserta didik.

Penelitian ini mengunakan teknik pengambilan data berupa observasi dan tes. Observasi merupakan teknik pengumpulan data melalui pengamatan langsung maupun tidak langsung dibantu dengan alat observasi (Sanjaya, 2013: 270). Dalam penelitian ini kegiatan observasi digunakan untuk mengamati keterlaksanaan kegiatan pemelajaran kegiatan guru saat mengajar di dalam kelas dengan menerapkan model pembelajaran Two Stay Two Stray dan Problem Based Learning yang dilakukan oleh seorang pengamat atau observer. Alat yang digunakan dalam kegitan observasi yaitu lembar observasi kinerja guru dalam melaksanakan model pembelajaran Two Stay Two Stray sebagai Kelas Eksperimen dan Problem Based Learning sebagi kelas kontrol. Tes merupakan kumpulan pertanyaan yang digunakan untuk mengetahui pengetahuan yang dimilki oleh peserta didik. Guna mengukur hasil belajar dengan teknik tes maka dalam penelitian ini mengunakan instrumen berupa tes pilihan ganda. Setelah data didapatkan selanjutnya dalam penelitian ini menggunakan serangkaian teknik analsisis data berupa teknik analisis deskriptif yang terdiri uji prasyarat terdiri atas uji normalitas dan uji homogenitas, seta uji hipotesis dengan mengunakan uji beda atau uji T (T-Test).

\section{HASIL DAN PEMBAHASAN}

Hasil penelitian ini terdiri atas analisis diskirptif, uji prasyarat, serta uji hipotesis dengan mengunakan uji beda atau uji $\mathrm{T}(T-T e s t)$. Uji prasyarat terdiri atas uji normalitas dan uji homogenitas. Penggunaan uji normalitas bertujuan guna mengetahi benarkah sempel yang dipakai pada penelitian ini berasal dari populasi yang berditribusi normal atau tidak. Tujuan uji homogenitas dilakukan guna mengetahui apakah kelas pada penelitian ini yaitu kelas eksperimen dan kelas kontrol homogen atau tidak.

Tabel 1

Hasil Analisis Deskriptif Pre-Test Hasil Belajar Tema 8 Kelas Eksperimen dan Kelas Kontrol Deskriptive Statistics

\begin{tabular}{|l|l|l|l|l|l|}
\hline & $\mathrm{N}$ & $\begin{array}{l}\text { Minimu } \\
\mathrm{m}\end{array}$ & $\begin{array}{l}\text { Maximu } \\
\mathrm{m}\end{array}$ & $\begin{array}{l}\text { Std. } \\
\text { Mean }\end{array}$ \\
\hline $\begin{array}{l}\text { Pre-Test } \\
\text { Eksperime } \\
\mathrm{n}\end{array}$ & 33 & 53 & 74 & 63.88 & 6.279 \\
\hline $\begin{array}{l}\text { Pre-Test } \\
\text { Kontrol }\end{array}$ & 31 & 53 & 74 & 62.00 & 5.060 \\
\hline $\begin{array}{l}\text { Valid N31 } \\
\text { (listwise) }\end{array}$ & & & & \\
\hline
\end{tabular}

Berdasarkan tabel 1, diperoleh data PreTest hasil belajar IPA menggunakan SPSS 24 for windows yang menunjukkan bahwa jumlah responden $(\mathrm{N})$ pada kelas eksperimen sebanyak 33 Peserta Didik dan mempunyai skor minimum 53 sedangkan skor maksimum sebesar 74 . Skor rata-rata (mean) pada kelas eksperimen adalah 63.88 dengan standar deviation sebesar 6.279. Sedangkan pada kelas kontrol mempunyai jumlah responden sebanyak 31 Peserta Didik. Skor minimum pada kelas kontrol sebesar 53 dan skor maksimum sebesar 74 dengan skor rata-rata (mean) 62.00 serta mempunyai standar deviation sebesar 5.060. Hasil pengolahan diatas dapat memperjelas gambaran pre-test hasil belajar Tema 8 pada kelas eksperimen dan kelas kontrol. Selanjutnya analisis deskriptif niali Pos-Test hasil 
407 Efektivitas Problem Based Learning dan Two Stay Two Stray dalam pencapaian hasil belajarWisnu Darmawan, Nyoto Harjono

belajar Tema 8 kelas eksperimen dan kelas kontrol.

Tabel 2

Hasil Analisis Deskriptif Post-test Hasil Belajar Tema 8 Kelas Eksperimen dan Kelas Kontrol Deskriptive Statistics

\begin{tabular}{|c|c|c|c|c|c|}
\hline & $\mathrm{N}$ & $\begin{array}{l}\text { Minim } \\
\text { um }\end{array}$ & $\begin{array}{l}\text { Maxi } \\
\text { mum }\end{array}$ & Mean & \begin{tabular}{|l} 
Std. \\
Devia \\
tion
\end{tabular} \\
\hline $\begin{array}{l}\text { Pos-Test } \\
\text { Eksperimen }\end{array}$ & 337 & 74 & 97 & 87.64 & 46.314 \\
\hline $\begin{array}{l}\text { Pos-Test } \\
\text { Kontrol }\end{array}$ & 317 & 71 & 91 & 78.32 & 25.082 \\
\hline $\begin{array}{l}\text { Valid N } \\
\text { (listwise) }\end{array}$ & 31 & & & & \\
\hline
\end{tabular}

Berdasarkan tabel 2 diatas, diperoleh data post-test hasil belajar Tema 8 menggunakan SPSS 24 for windows yang menunjukkan bahwa jumlah responden $(\mathrm{N})$ pada kelas eksperimen sebanyak 33 Peserta Didik dan mempunyai skor minimum 74 sedangkan skor maksimum sebesar 97. Skor rata-rata (mean) pada kelas eksperimen adalah 87.64 dengan standar deviation sebesar 6.314. Sedangkan pada kelas kontrol mempunyai jumlah responden sebanyak 31 Peserta Didik. Skor minimum pada kelas kontrol sebesar 71 dan skor maksimum sebesar 91 dengan skor rata-rata (mean) 78.32 serta mempunyai standar deviation sebesar 5.082. Hasil pengolahan diatas dapat memperjelas gambaran post-test hasil belajar Tema 8 pada kelas eksperimen dan kelas kontrol.

\section{Tabel 3}

Hasil Uji Normalitas Data Pre-Test dan PosTest Hasil Belajar Peserta Didik

Tests of Normality

\begin{tabular}{|l|l|l|l|l|l|}
\hline \multirow{3}{*}{} & \multicolumn{3}{|c|}{$\begin{array}{l}\text { Kolmogorov- } \\
\text { Smirnov }\end{array}$} & \multicolumn{2}{|c|}{ Shapiro-Wilk } \\
\cline { 2 - 5 } & Kelas & Statistic df & Sig. & $\begin{array}{l}\text { Statist } \\
\text { ic }\end{array}$ & df \\
\hline
\end{tabular}

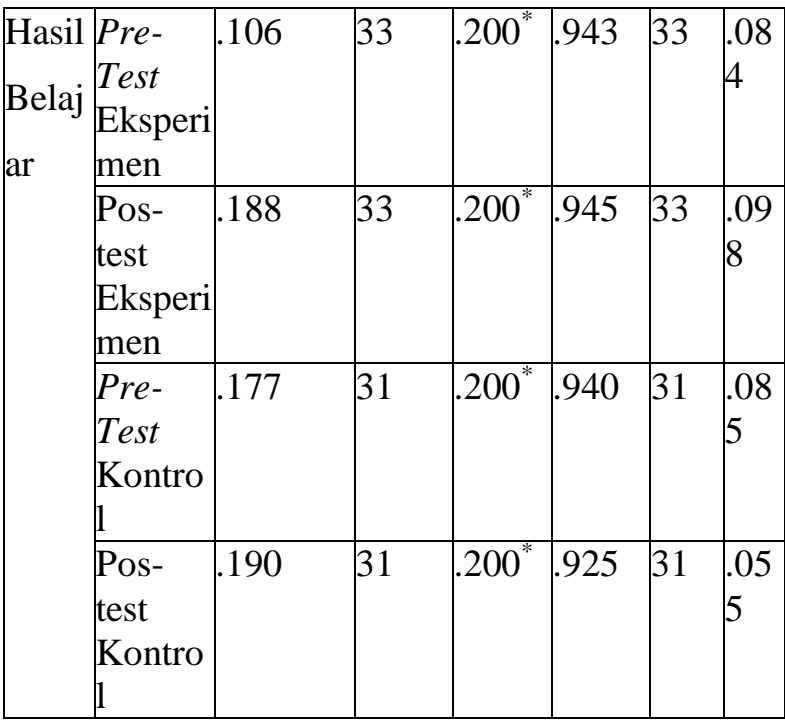

Berdasarkan tabel 3 dapat diketahui bahwa uji normalitas menunjukkan nilai signifikansi pada kolom Kolmogrov-Smirnov hasil belajar pre-test kelas Eksperimen sebesar 0,200 pada dan pada kolom Shapiro-Wilk menunjukkan nilai signifikansi sebesar 0,084 . Nilai signifikansi 0,200 dan 0,084 memiliki nilai lebih tinggi dari $0,005 \quad((0,200>0,005)$ $(0,084>0,005))$. Lalu uji normalitas pada hasil belajar post-test kelas eksperimen memiliki nilai signifikansi pada kolom Kolmogrov-Smirnov sebesar 0,200 dan nilai signifikansi sebesar 0,098 pada kolom Shapiro-Wilk. Nilai signifikansi 0,200 dan 0,098 merupakan nilai signifikansi yang lebih dari $0,005 \quad((0,200>0,005)$ $(0,098>0,005))$ dengan demikian mampu disimpulkan bahwa Pre-Test dan Post-Test hasil belajar tema 8 kelas eksperimen dinyatakan normal.

Uji normalitas menunjukan hasil belajar Pre-test kelas kontrol memiliki nilai signifikansi pada Kolmogrov-Smirnov sebesar 0,200 dan nilai signifikansi sebesar 0,085 pada kolom ShapiroWilk. Nilai signifikansi 0,200 dan 0,085 merupakan nilai signifikansi yang lebih dari 
408 Efektivitas Problem Based Learning dan Two Stay Two Stray dalam pencapaian hasil belajarWisnu Darmawan, Nyoto Harjono

$0,005((0,200>0,005)(0,085>0,005))$ kemudian hasil belajar post-test kelas kontrol memiliki nilai signifikansi pada Kolmogrov-Smirnov sebesar 0,200 dan nilai signifikansi sebesar 0,098 pada kolom Shapiro-Wilk. Nilai signifikansi 0,200 dan 0,055 merupakan nilai signifikansi yang lebih dari $0,005((0,200>0,005)(0,055>0,005))$ dengan demikian mampu disimpulkan bahwa hasil belajar pre-test dan pos-test kelas kontrol dinyatakan normal.

Tabel 4.

Hasil Uji Homogenitas Pre-Test Hasil Belajar Peserta Didik

Test of Homogeneity of Variances

\begin{tabular}{|c|c|c|c|c|c|}
\hline & $\begin{array}{l}\text { Levene } \\
\text { Statistic }\end{array}$ & df1 & df2 & Sig. \\
\hline \multirow[t]{4}{*}{$\begin{array}{l}\text { Hasil } \\
\text { Belajar }\end{array}$} & $\begin{array}{l}\text { Based on } \\
\text { Mean }\end{array}$ & 1.705 & 1 & 62 & .196 \\
\hline & $\begin{array}{l}\text { Based on } \\
\text { Median }\end{array}$ & 1.662 & 1 & 62 & .202 \\
\hline & $\begin{array}{l}\text { Based on } \\
\text { Median and } \\
\text { with adjusted } \\
\text { df }\end{array}$ & 1.662 & 1 & & 202 \\
\hline & $\begin{array}{l}\text { Based on } \\
\text { trimmed mean }\end{array}$ & 1.655 & 1 & 62 & .203 \\
\hline
\end{tabular}

Sesusi dengan hasil uji homogenitas pada Pre-Test hasil belajar tema 8 peserta didik baik pada kelas eksperimen maupun kelas kontrol. Menunjukan bahwa nilai Based on Mean signifikansi sebesar 0,196 . Sesuai dengan nilai signifikansi 0,196 lebih dari 0,005 $(0,196>0,005)$ dengan demikian mampu disimpulkan bahwa hasil belajar pre-test kelas eksperimen dan kelas kontrol dinyatakan homogen.
Tabel 5

Hasil Uji Homogenitas Post-Test Hasil Belajar Peserta Didik

Test of Homogeneity of Variances

\begin{tabular}{|c|c|c|c|c|c|}
\hline & $\begin{array}{l}\text { Levene } \\
\text { Statistic }\end{array}$ & df1 & $\mathrm{df} 2$ & Sig. \\
\hline \multirow{4}{*}{$\begin{array}{l}\text { Has } \\
\text { il } \\
\text { Bel } \\
\text { ajar }\end{array}$} & Based on Mean & 2.459 & 1 & 62 & .122 \\
\hline & Based on Median & 2.544 & 1 & 62 & .116 \\
\hline & $\begin{array}{l}\text { Based on Median } \\
\text { and with } \\
\text { adjusted df }\end{array}$ & 2.544 & 1 & $\begin{array}{r}61 . \\
77 \\
3\end{array}$ & .116 \\
\hline & $\begin{array}{l}\text { Based on } \\
\text { trimmed mean }\end{array}$ & 2.175 & 1 & 62 & .145 \\
\hline
\end{tabular}

homogenitas pada pos-test hasil belajar tema 8 peserta didik baik pada kelas eksperimen maupun kelas kontrol. Menunjukan bahwa nilai Based on Mean signifikansi sebesar 0,122 . Sesuai dengan nilai signifikansi 0,122 lebih dari 0,005 $(0,122>0,005)$ dengan demikian mampu disimpulkan bahwa post-test hasil belajar kelas eksperimen dan kelas kontrol dinyatakan homogen.

Tabel 6.

Uji T Hasil Belajar Peserta Didik Independent Samples Test

\begin{tabular}{|c|c|c|c|c|c|c|c|c|}
\hline & \multicolumn{2}{|c|}{$\begin{array}{c}\text { Levene' } \\
\text { s Test } \\
\text { for } \\
\text { Equalit } \\
\text { y of } \\
\text { Varianc } \\
\text { es }\end{array}$} & \multicolumn{5}{|c|}{ t-test for Equality of Means } \\
\hline & & $\mathrm{F}$ & Sig. & $\mathrm{t}$ & $\mathrm{df}$ & $\begin{array}{c}\text { Sig. } \\
(2- \\
\text { taile } \\
\text { d) }\end{array}$ & MD & SED \\
\hline & $\begin{array}{l}\text { EV } \\
\text { A }\end{array}$ & $\begin{array}{r}2.45 \\
9\end{array}$ & .122 & \begin{tabular}{|r}
6.47 \\
5
\end{tabular} & 62 & .000 & $\begin{array}{r}9.31 \\
4\end{array}$ & $\begin{array}{r}1.43 \\
8\end{array}$ \\
\hline & \begin{tabular}{|l} 
EV \\
N \\
A
\end{tabular} & & & $\begin{array}{r}6.51 \\
9\end{array}$ & $\begin{array}{r}60 . \\
60 \\
9\end{array}$ & .000 & $\begin{array}{r}9.31 \\
4\end{array}$ & $\begin{array}{r}1.42 \\
9\end{array}$ \\
\hline
\end{tabular}

Keterangan tabel 6

$\mathrm{HB}=$ Hasil Belajar 
409 Efektivitas Problem Based Learning dan Two Stay Two Stray dalam pencapaian hasil belajarWisnu Darmawan, Nyoto Harjono

EVA =Equal variances assumed

EVNA $=$ Equal variances not assumed

MD =Mean Difference

SED $=$ Std. Error Difference

Berdasarkan hasil uji $\mathrm{t}$ yang terlihat

dalam kolom kolom equal variances assumed.

Dalam kolom equal variances assumed menunjukkan nilai t sebesar 6.475. melalui kolom equal variances assumed juga diketahui nilai signifikansi (2-tailed) hasil belajar peserta didik setelah diberikan perlakuan sebesar 0,000 lebih kecil dari $0,005(0,000<0,005)$. Sesuai dengan dasar pengambilan keputusan nilai signifikansi (2-tailed) hasil belajar peserta didik dapat dinyatakan terdapat perbedaan rata-rata yang signifikansi antara hasil belajar peserta didik kelas eksperimen dan kelas kontrol. Berdasarkan hasil analisis data pada tabel uji t kolom sign. (2tailed) dilakukan uji hipotesis. Uji hipotesis pada penelitian ini adalah:

$\mathrm{H}_{0}$ : Tidak memiliki perbedaan efektivitas hasil belajar pada peserta didik yang mendapat penerapan pembelajaran model pembelajaran Two Stay Two Stray Problem dan Based Learning

Ha: Terdapat perbedaan efektivitas hasil belajar pada peserta didik yang mendapat penerapan pembelajaran model Two Stay Two Stray Problem dan Based Learning.

Perbedaan efektivitas pada penelitian ini dapat diketahui dari nilai signifikansi (2-tailed) melalui hasil uji beda pada tabel uji t bagian kolom t-test for Equality of Means. Sesuai dengan pengambilan keputusan perbedaan efektivitas didasarkan pada nilai signifikansi (2tailed) pada H0 dan Ha. Jika Ho `menunjukan nilai signifikansi (2-tailed) lebih besar 0,005
$(>0,005)$ maka tidak memiliki perbedaan efektivitas hasil belajar pada peserta didik yang mendapat penerapan pembelajaran model pembelajaran Two Stay Two Stray Problem dan Based Learning. Sedangkan jika Ha menunjukan nilai signifikansi (2-tailed) lebih kecil dari besar 0,005 $(<0,005)$ maka terdapat perbedaan efektivitas hasil belajar pada peserta didik yang mendapat penerapan model pembelajaran $T w o$ Stay Two Stray dan Problem Based Learning. Berdasarkan hasil uji $t$ pada tabel uji $t$ dalam kolom t-test for Equality of Means menunjukan signifikansi (2-tailed) sebesar 0,000, dan nilai tersebut lebih kecil dari $0,005 \quad(0,000<0,005)$ maka dapat disimpulkan bahwa Ha diterima dan artinya terdapat perbedaan efektivitas hasil belajar yang signifikansi antara model pembelajaran Two Stay Two Stray dan Problem Based Learning

\section{UCAPAN TERIMA KASIH}

Peneliti sekaligus penulis ingin mengucapkan terimaksaih kepada seluruh pihak yang sudah membantu serta memudahkan pada serangkaian proses dalam penelitian eksperimen ini. Terkhusus dan yang terutama kepada Tuhan karena telah mebimbing dan memberi kemudahan disetiap peroses dalam penelitian, kemudian ucapan terimakasih kepada dosen pembimbing, dan keluarga serta teman-teman

Ucapan terimaksaih juga dihaturkan kepada pihak sekolah yaitu SD Negeri Blotongan 02 dan SD Negeri Sidorejo Lor 05 karena telah membantu penulis dalam melakukan penelitian.

\section{SIMPULAN}


410 Efektivitas Problem Based Learning dan Two Stay Two Stray dalam pencapaian hasil belajarWisnu Darmawan, Nyoto Harjono

Hasil dari analisis data penelitian ini selanjutnya mengarah pada penarikan kesimpulan yang menjelaskan bahwa terdapat perbedaan efektivitas yang signifikan antara penerapan model pembelajaran Two Stay Two Stray di SD Negeri Blotongan 02 dan Problem Based Learning diterapkan di SD Negeri Sidorejo Lor 05 terhadap pencapaian hasil belajar peserta didik kelas 4 pada pembelajaran tema 8. Kesimpulan ini telah dibuktikan dengan serangkaian hasil uji pengolahan data diantaranya, uji hipotesis berdasarkan hasil uji t. Melalui hasil uji t yang menunjukan nilai thitung sebasar 6.475 yang terletak pada kolom equal variances assumed. Berdasarkan kolom equal variances assumed juga mampu diketahui bahwa nilai signifiknasi (2-tained) pos-test hasil belajar peserta didik sebesar 0,000. Kolom equal variances assumed diketahui bahwa nilai signifiknasi (2-tained) posttest hasil belajar peserta didik sebesar 0,000 yang artinya lebih kecil dari $0,005 \quad(0,000<0,005)$. Sesuai dengan dasar pengambilan keputusan signifkansi (2-tailed) pada hasil belajar pos-test peserta didik dinyatakan terdapat perbedaan ratarata yang signifikan pada hasil belajar pos-test peserta didik pada kelas eksperimen dan kelas kontrol yang mimiliki nilai Mean Difference sebesar 9.314.

Berdasarkan hasil skor rata-rata hasil belajar pos-test peserta didik pada kelas eksperimen dan kelas kontrol yang memiliki perbedaan yang signifikan. Kelas eksperimen dengan menerapkan Two Stay Two Stray mempunyai skor rata-rata pada hasil belajar postest sebesar 87.64 sedangkan skor rata-rata hasil belajar pos-test kelas kontrol yang menerapakan model Problem Based Learning sebesar 78.32. dapat dinyatakan bahwa skor rata-rata pada hasil belajar pos-test kelas eksperimen dengan penerapan model Two Stay Two Stray lebih besar dari skor rata-rata kelas kontrol dengan penerapan model Problem Based Learning (87.64 >78.32). Berdasarkan hasil tersebut dapat disimpulkan bahwa hasil belajar peserta didik kelas 4 Tema 8 Daerah Tempat Tinggalku Subtema 1 Linkungan Tempat Tingalku Pembelajaran 1 pada kelas eksperimen dengan menerapakan model pembelajaran Two Stay Two Stray lebih efektif jika dibandingkan dengan kelas kontrol yang menerapkan model pembelajaran Problem Based Learning.

\section{DAFTAR PUSTAKA}

Abdurrozak, R., Kurnia, A. J., \& isrok, a. (2016). Pengaruh Model Problem Based Learning Terhadap Kemampuan Berpikir Kreatif Siswa . Pena ilmiah, Vol,1 No, 1.

Dewi, A.M., Dibia., Sudana, N. (2013). Pengaruh Model Pembelajaran Problem Based Learning (PBL) Berbantuan Media Video Terhadap Hasil Belajar IPA Kelas IV SD Negeri Pergung. Universitas Pendidikan Ganesha, Vol,1 No, 1.

Dewi, S. (2014). Pengaruh Pendekatan Contextual Teaching And Learning (CTL) Dan Kosentrasi Belajar Terhadap Efektivitas Belajar Siswa Pada Mata Pelajaran Matematika Kelas VII SMP N 8 Kota Jambi. Jurnal Ilmiah Universitas Batanghari Jambi, Vol,14 No, 4.

Hosnan. (2014). Pendekatan Saintifik dan Kontekstual dalam Pembelajaran IPA. Jakarta: PT. Bumi Aksara.

Huda, Miftahul. (2013). Model-model Pengajaran dan Pembelajaran.Yogyakarta: Pustaka Pelajar. 
411 Efektivitas Problem Based Learning dan Two Stay Two Stray dalam pencapaian hasil belajarWisnu Darmawan, Nyoto Harjono

Jamil, S. (2014). Strategi Pembelajaran. Yogyakarta: Ar-Ruzz Media

Mulyasa, E. (2014). Pengembangan dan Implemenatasi Kurikulum 2013 . Bandung : Rosda.

Permendikbud No. 65 tahun (2013) tentang Standar Proses bahwa pembelajaran tematik terpadu di SD/MI/SDLB/Paket A

Purwanto. (2014). Evaluasi Hasil Belajar Yogyakarta. Pustaka Belajar.

Djuramang, R.R. (2018) Pengaruh Model Pembelajaran Kooperatif Tipe Two Stay Two Stray Dan Tipe Giving Question And Getting Answer Terhadap Keaktifan Dan Hasil Belajar Siswa Pada Materi Sistem Ekskresi. Jurnal Pendidikan Glasser, Vol,2 No, 1.

Sanjaya, Wina. (2013). Penelitian Pendidikan. Jakarta: Prenada Media Group.

Shoimin, Aris. (2014). 68 Model Pembelajaran Inovatif dalam Kurikulum 2013. Yogyakarta: Ar-RuzzMedia.

Susanto. (2015). Teori Belajar dan Pembelajaran di Sekolah Dasar. Jakarta: Kencana Prena Media.

Sutikno, Sobry. (2014). Metode \& Model-Model Pembelajaran Menjadikan ProsesPembelajaran Lebih Variatif, Aktif, Inovatif, Efektif, dan Menyenangkan. Lombok: Holistica.

Trianto. (2011). Model-model Pembelajaran Inovatif. Jakarta: Prestasi Pustaka. 